\title{
Growth in utero and during childhood among women who develop coronary heart disease: longitudinal study
}

\author{
T Forsén, J G Eriksson, J Tuomilehto, C Osmond, D J P Barker
}

\begin{abstract}
Objective To examine whether women who develop coronary heart disease have different patterns of fetal and childhood growth from men in the same cohort who develop the disease.

Design Follow up study of women whose body size at birth was recorded and who had an average of 10 measurements of height and weight during childhood.

Setting Helsinki, Finland.

Subjects 3447 women who were born in Helsinki University Central Hospital during 1924-33 and who went to school in Helsinki.

Main outcome measures Hazard ratios for hospital admission for or death from coronary heart disease. Results Coronary heart disease among women was associated with low birth weight $(\mathrm{P}=0.08$ after adjustment for gestation, $\mathrm{P}=0.007$ after adjustment for placental weight) and was more strongly associated with short body length at birth $(\mathrm{P}=0.001$ and $\mathrm{P}<0.0001$, respectively). The hazard ratio for women developing coronary heart disease increased by $10.2 \%$ (95\% confidence interval 4.3 to 15.7$)$ for each $\mathrm{cm}$ decrease in length at birth. The effect of short length at birth was greatest in women whose height "caught up" after birth so that as girls they were tall. Such girls tended to have tall mothers. In contrast, men in the same cohort who developed the disease were thin at birth rather than short, showed "catch up" growth in weight rather than height, and their mothers tended to be overweight rather than tall. Conclusion Coronary heart disease among both women and men reflects poor prenatal nutrition and consequent small body size at birth combined with improved postnatal nutrition and "catch up" growth in childhood. The disease is associated with reductions in those aspects of body proportions at birth that distinguish the two sexes-short body length in women and thinness in men.
\end{abstract}

\section{Introduction}

In both men and women the development of coronary heart disease has been shown to be associated with low birth weight in relation to the length of gestation. ${ }^{1-3}$ An interpretation of this is that coronary heart disease originates through adaptations that the fetus makes when it is undernourished. ${ }^{4}$ These adaptations include alterations in metabolism, hormonal output, and the distribution of cardiac output, and they may be combined with slowing of growth. ${ }^{5}$ Birth weight is a crude marker of fetal growth, as the same birth weight may be the outcome of many different paths of growth. ${ }^{6}$ Insights into the fetal adaptations that lead to coronary heart disease have come from studying body proportions at birth. Thinness at birth and shortness at birth-outcomes of different paths of reduced fetal growth-have been found to be associated with different biological risk factors for coronary heart disease. ${ }^{4}$ Placental weight has also been found to be an independent predictor of coronary heart disease in some studies. $^{78}$

We have previously described death rates from coronary heart disease among a group of men who were born in Helsinki during $1924-33 .^{89}$ Their body size at birth was recorded in detail. As expected coronary heart disease was associated with low birth weight, after adjustment for gestation, but was more strongly associated with thinness at birth, measured by a low ponderal index (birth weight/length ${ }^{3}$ ). The growth of these men through childhood and their living conditions were also recorded. This allowed us to examine for the first time the association between childhood growth and death from coronary heart disease, taking into account size at birth. We found that the highest death rates from coronary heart disease occurred in boys who were thin at birth but whose weight caught up so that they had an above average body mass from the age of 7 years.

We report here findings among the corresponding cohort of women born in the same hospital over the same period of time. The tempo of fetal and childhood growth differs in boys and girls. ${ }^{11}{ }^{11}$ Hence the paths of early growth that lead to coronary heart disease may differ in the two sexes.

\section{Methods}

We studied a sample of women who were born at the University Central Hospital during 1924-33 and who went to school in the city of Helsinki; $60 \%$ of all births in the city occurred in this hospital. Details of the birth records kept there have been previously described. Data on the mothers include age, parity, height, and date of last menstrual period, together with body weight measured on admission in labour. Data on their newborn babies include birth weight, length, head circumference, and placental weight. We studied women who were born at the hospital and who went to school in the city of Helsinki and were still resident in Finland in 1971. School health records for all children attending school in Helsinki are stored in the city archive. Details of these records have been described previously. ${ }^{9}$ They include an average of 10 (SD 4) measurements of length and weight between the ages of 6 and 16 years, recorded at periodic medical examinations. They also include the number of other people living in the child's home-recorded at the time of first examination-and the number of rooms. Since 1971 all residents of Finland have been assigned a unique personal identification number.

From the birth and school health records and identification numbers we identified 3688 women who fulfilled the criteria. Of these women, 241 subsequently emigrated, and the date of emigration was not always recorded. We therefore excluded them from the study to leave 3447.

\author{
National Public \\ Health Institute, \\ Department of \\ Epidemiology and \\ Health Promotion, \\ Diabetes and \\ Genetic \\ Epidemiology Unit \\ Mannerheimintie \\ 166, Helsinki, \\ Finland \\ T Forsén \\ research fellow \\ J G Eriksson \\ senior researcher \\ J Tuomilehto \\ professor \\ Medical Research \\ Council \\ Environmental \\ Epidemiology Unit, \\ University of \\ Southampton, \\ Southampton \\ General Hospital, \\ Southampton \\ SO16 6YD \\ C Osmond \\ statistician \\ D J P Barker \\ director \\ Correspondence to: \\ D J P Barker \\ david.barker@mrc. \\ soton.ac.uk
}

BMJ 1999;319:1403-7 
Table 1 Maternal, neonatal, and childhood characteristics of 3447 women born at Helsinki University Central Hospital during 1924-33

\begin{tabular}{|c|c|c|c|}
\hline Detail & Mean (SD) & Range & $\begin{array}{l}\text { No of missing } \\
\text { values }\end{array}$ \\
\hline \multicolumn{4}{|l|}{ Maternal } \\
\hline Height (m) & $1.58(0.06)$ & $1.04-1.86$ & 245 \\
\hline Weight in late pregnancy $(\mathrm{kg})$ & $66.8(8.7)$ & $45-134$ & 261 \\
\hline Body mass index in late pregnancy $\left(\mathrm{kg} / \mathrm{m}^{2}\right)$ & $26.7(3.1)$ & $19.4-51.1$ & 285 \\
\hline Age (years) & $27.7(5.8)$ & $15-48$ & 9 \\
\hline Age at menarche (years) & $15(1.7)$ & $9-28$ & 7 \\
\hline Primiparous (\%) & $1445 / 3444(42)$ & & 3 \\
\hline \multicolumn{4}{|l|}{ Neonate } \\
\hline Birth weight $(\mathrm{g})$ & $3315(493)$ & $1470-5600$ & 0 \\
\hline Head circumference $(\mathrm{cm})$ & $34.3(1.4)$ & $28.0-39.0$ & 10 \\
\hline Birth length $(\mathrm{cm})$ & $49.7(2.0)$ & $38.0-59.0$ & 12 \\
\hline Ponderal index $\left(\mathrm{kg} / \mathrm{m}^{3}\right)$ & $26.9(2.4)$ & $15.6-50.0$ & 12 \\
\hline Placental weight $(\mathrm{g})$ & $628(125)$ & $200-1290$ & 7 \\
\hline Length of gestation (days) & $276(15)$ & $197-307$ & 179 \\
\hline Born before 37 weeks' gestation (\%) & 10.1 & & 179 \\
\hline \multicolumn{4}{|l|}{ Child $^{*}$} \\
\hline \multicolumn{4}{|l|}{ Height $(\mathrm{m})$ at age (years): } \\
\hline 7 & $1.19(0.05)$ & $0.98-1.37$ & 0 \\
\hline 11 & $1.39(0.06)$ & $1.13-1.61$ & 0 \\
\hline 15 & $1.58(0.06)$ & $1.29-1.81$ & 0 \\
\hline \multicolumn{4}{|l|}{ Weight $(\mathrm{kg})$ at age (years): } \\
\hline 7 & $21.7(2.9)$ & $14.1-37.9$ & 0 \\
\hline 11 & $32.1(5.1)$ & $18.2-64.5$ & 0 \\
\hline 15 & $49.7(7.7)$ & $26.2-92.9$ & 0 \\
\hline \multicolumn{4}{|l|}{ Body mass index $\left(\mathrm{kg} / \mathrm{m}^{2}\right)$ at age (years): } \\
\hline 7 & $15.3(1.3)$ & $11.7-24.1$ & 0 \\
\hline 11 & $16.5(1.7)$ & $12.2-31.2$ & 0 \\
\hline 15 & $19.8(2.5)$ & $12.3-41.2$ & 0 \\
\hline \multicolumn{4}{|l|}{ Housing } \\
\hline No of people in house & $4.5(1.5)$ & $2-14$ & 570 \\
\hline No of rooms in house & $1.7(0.8)$ & $1-7$ & 536 \\
\hline Crowding (No of people/No of rooms) $\dagger$ & $2.8(1.6)$ & $0.6-11$ & 576 \\
\hline
\end{tabular}

*Height, weight, and body mass index at each age were estimated from serial measurements on each child (see text).

†Log transformed.

By using the personal identification number we identified all hospital admissions and deaths among the women during 1971-95. Because death rates from coronary heart disease are much lower among women than men we ascertained fatal and non-fatal coronary disease rather than fatal disease alone, as in our study of men. All hospital admissions in Finland are recorded in the national hospital discharge register. All deaths are recorded in the national mortality register. Causes of hospital admissions or deaths were recorded according to ICD-8 (international classification of diseases, 8 th revision) until 1986; thereafter ICD-9 was used until 1995. The first three digits from the cause of admission or death were used to identify the occurrence of coronary heart disease (ICD-8 and ICD-9 codes 410-414). Using the father's occupation, which was on the birth records, we grouped the men according to a social classification used by the Central Statistical Office. Overall, $85 \%$ of the fathers were labourers, and $11 \%$ were classified as lower middle class. Together these constitute the lower social class as opposed to the upper social class.

Statistical analysis-We examined the trends in hazard ratios with maternal, neonatal, and childhood measurements. Tests for trend were based on Cox's proportional hazards model. We converted each measurement of height, weight, and body mass index for each girl to a $\mathrm{Z}$ score. ${ }^{12}$ We interpolated between successive $\mathrm{Z}$ scores with a piecewise linear function and so obtained a $\mathrm{Z}$ score at each birthday from age 7 to 15 years. We back transformed these $\mathrm{Z}$ scores to obtain the corresponding height, weight, and body mass index at these ages.

\section{Results}

Maternal, neonatal, and childhood characteristics of the 3447 women are shown in table 1 . Of these women, 247 had been admitted to hospital for coronary heart disease, of whom 35 died from the disease. A further 32 had died without admission to hospital. We therefore analysed data on 279 women with coronary heart disease. The annual death rate at ages 45 to 64 years was 0.8 per 1000 compared with 3.9 per 1000 in men.

\section{Size at birth}

Table 2 shows hazard ratios for coronary heart disease according to size at birth. The ratios fell with increasing birth weight, although this was not significant. Hazard ratios were not related to the length of gestation, but adjustment for gestation strengthened the association with birth weight. Hazard ratios fell more steeply with increasing length. The hazard ratio for developing coronary heart disease increased by $10.2 \% \quad(95 \%$ confidence interval 4.3 to 15.7 ) for each $\mathrm{cm}$ decrease in length at birth, adjusted for gestation. There were no trends with head circumference or ponderal index.

Hazard ratios tended to rise with increasing placental weight, although this trend was not significant. There was, however, a significant rise with an increasing ratio of placental weight to birth weight ( $\mathrm{P}=0.01$, adjusted for gestation). In a simultaneous analysis with birth weight, placental weight, and gestational age the hazard ratios fell with increasing birth weight $(\mathrm{P}=0.007)$ but rose with increasing placental weight $(\mathrm{P}=0.03)$. There were stronger trends in a simultaneous analysis of birth length, placental weight, and gestational age, the hazard ratios falling with increasing birth length $(\mathrm{P}<0.0001)$ and rising with increasing placental weight $(\mathrm{P}=0.02)$. The hazard ratios increased by $13.8 \%$ (7.5 to 19.6) for each $\mathrm{cm}$ decrease in length at birth and increased by $14.8 \%$ (2.6 to 28.3) for each $100 \mathrm{~g}$ increase in placental weight. The trends with length and placental weight were similar for fatal and non-fatal disease.

Table 3 shows hazard ratios according to length and placental weight. Because the relative size of the body and placenta change during gestation we excluded preterm babies. Compared with women who were longest at birth but had the lowest placental weight, whose hazard ratio was set at 1.0, the highest ratio, 5.2, was in women who were short at birth but had heavy placentas.

\section{Growth in childhood}

At each age from 7 to 15 years the mean heights and weights of women who developed coronary heart disease were below those of all other women. At 7 years, for example, their height was $0.42 \mathrm{~cm}$ less and their weight $0.20 \mathrm{~kg}$ less. At no age, however, were the differences significant. At birth their length was 0.17 SD below average; while at 7 and 15 years their heights 
were only $0.08 \mathrm{SD}$ and $0.02 \mathrm{SD}$ below average, respectively. Therefore their heights and weights had largely "caught up" between birth and 15 years. Table 4 shows the combined effects of length at birth and height in childhood on hazard ratios for coronary heart disease. Height at 7 years is used but the findings with all other ages are similar. The hazard ratio for women who were longest at birth and tallest as children is set at 1.0. The fall in risk of coronary heart disease with increasing length at birth was steeper among women who were tallest as girls. This interaction between birth length and childhood height was significant $(\mathrm{P}=0.02)$. At no age in childhood was body mass index related to later coronary heart disease.

\section{Maternal characteristics}

The mothers' heights and their weights and body mass indices during pregnancy were unrelated to the occurrence of coronary heart disease in their daughters. When, however, we divided the mothers according to their height, using the median height of 1.58 metres as in our previous analysis, we found that the interactive effects of short length at birth and tallness in childhood on coronary heart disease was stronger among the daughters of taller women $(\mathrm{P}=0.006$ for interaction between birth length and height at 7 years in daughters of tall women). As expected, taller mothers tended to have taller daughters, the correlation coefficient between mother's height and daughter's height at 7 years being 0.36 .

\section{Crowding in the home and social class during childhood}

An examination of the average number of inhabitants and rooms in the homes where the girls grew up showed that $47 \%$ of them lived in homes with only one room (see table 1). We used the ratio of the number of inhabitants to the number of rooms as an index of crowding. Table 5 shows that families living in less crowded homes were of higher social class, and the daughters were taller at all ages. Coronary heart disease, however, was unrelated to the number of inhabitants, number of rooms, crowding, or social class in childhood.

\section{Sex differences in fetal growth}

In comparison with the men in the cohort the women had smaller head circumferences at birth $(34.3 \mathrm{~cm} v$ $34.9 \mathrm{~cm})$, shorter body lengths at birth $(49.7 \mathrm{~cm} v 50.2$ $\mathrm{cm})$, and lower birth weights (3315 g v $3443 \mathrm{~g})$. Mean placental weights, however, were similar (628 g v 634 g). During childhood the heights and weights of the men and women were similar until adolescence when, as expected, women became shorter and heavier. Table 6 , which gives the percentage of girls among term babies according to length at birth and placental weight, shows that the small differences in average body size at birth between the sexes conceal large differences in proportionate size. Short body length in relation to high placental weight, the pattern which predicts coronary heart disease in women (table 3), is much more common among girls than boys $(\mathrm{P}<0.0001$; table 6$)$. In contrast, table 7 shows that thinness at birth in relation to a large head circumference is much more common among boys than girls $(\mathrm{P}<0.0001)$; and it is thinness at birth that predicts coronary heart disease in men.
Table 2 Hazard ratios for coronary heart disease according to size at birth and height at age 7 years

\begin{tabular}{|c|c|c|c|c|c|}
\hline \multirow[b]{2}{*}{ Variable } & \multirow[b]{2}{*}{ No of women } & \multirow{2}{*}{$\begin{array}{l}\text { Hazard ratio } \\
\text { (No of cases) }\end{array}$} & \multicolumn{3}{|c|}{$P$ value } \\
\hline & & & Unadjusted & Adjusted* & Adjusted† \\
\hline \multicolumn{6}{|c|}{ Birth weight $(\mathrm{g})$ : } \\
\hline$\leqslant 2500$ & 191 & $1.34(17)$ & \multirow{5}{*}{0.20} & \multirow{5}{*}{0.08} & \multirow{5}{*}{0.007} \\
\hline-3000 & 708 & $1.38(63)$ & & & \\
\hline-3500 & 1420 & $1.24(117)$ & & & \\
\hline-4000 & 880 & $1.17(66)$ & & & \\
\hline$>4000$ & 248 & $1.00(16)$ & & & \\
\hline \multicolumn{6}{|c|}{ Birth length $(\mathrm{cm})$ : } \\
\hline$\leqslant 48$ & 726 & $1.65(71)$ & \multirow{5}{*}{0.01} & \multirow{5}{*}{0.001} & \multirow{5}{*}{$<0.0001$} \\
\hline-49 & 595 & $1.51(50)$ & & & \\
\hline-50 & 1077 & $1.41(89)$ & & & \\
\hline-51 & 588 & $1.17(40)$ & & & \\
\hline$>51$ & 449 & $1.00(26)$ & & & \\
\hline \multicolumn{6}{|c|}{ Ponderal index at birth $\left(\mathrm{kg} / \mathrm{m}^{3}\right)$ : } \\
\hline$\leqslant 25$ & 689 & $0.92(52)$ & \multirow{4}{*}{0.42} & \multirow{4}{*}{0.41} & \multirow{4}{*}{0.51} \\
\hline-27 & 1094 & $1.00(91)$ & & & \\
\hline-29 & 1004 & $0.97(80)$ & & & \\
\hline$>29$ & 648 & $1.00(53)$ & & & \\
\hline \multicolumn{6}{|c|}{ Height $(\mathrm{cm})$ at age 7 : } \\
\hline$\leqslant 116$ & 972 & $1.17(82)$ & \multirow{4}{*}{0.34} & \multirow{4}{*}{ - } & \\
\hline-119 & 800 & $1.21(69)$ & & & \\
\hline-122 & 773 & $1.26(66)$ & & & \\
\hline$>122$ & 902 & $1.00(62)$ & & & \\
\hline
\end{tabular}

${ }^{*}$ Adjusted for gestation.

†Adjusted for gestation and placental weight.

Table 3 Hazard ratios for coronary heart disease according to length at birth and placental weight in women born at term. Number of cases in parentheses

\begin{tabular}{lcccc} 
& \multicolumn{5}{c}{ Length at birth $(\mathbf{c m})$} \\
\cline { 2 - 5 } Placental weight $\mathbf{g})$ & $\mathbf{\$ 4 8}$ & $\mathbf{- 4 9}$ & $\mathbf{- 5 0}$ & $\mathbf{5 0 0}$ \\
\hline-500 & $3.4(30)$ & $1.7(7)$ & $2.1(9)$ & $1.0(3)$ \\
\hline-600 & $2.9(24)$ & $3.5(25)$ & $1.6(20)$ & $2.4(19)$ \\
\hline-700 & $3.3(11)$ & $2.6(13)$ & $3.1(36)$ & $1.7(18)$ \\
\hline$>700$ & $5.2(6)$ & $2.2(5)$ & $3.8(23)$ & $1.9(26)$ \\
\hline
\end{tabular}

Table 4 Hazard ratios for coronary heart disease according to length at birth, adjusted for gestation and placental weight, and height at age 7 years. Numbers of cases in parentheses

\begin{tabular}{lcccc} 
& \multicolumn{5}{c}{ Height at age 7 years $\mathbf{( c m )}$} \\
\cline { 2 - 5 } Birth length $(\mathbf{c m})$ & $\leqslant \mathbf{1 1 6}$ & $\mathbf{- 1 1 9}$ & $\mathbf{- 1 2 2}$ & $>\mathbf{1 2 2}$ \\
\hline$\leqslant 48$ & $3.3(27)$ & $3.4(16)$ & $2.4(10)$ & $5.6(16)$ \\
\hline-49 & $2.5(14)$ & $2.5(11)$ & $3.1(11)$ & $2.6(9)$ \\
\hline-50 & $2.4(23)$ & $2.6(23)$ & $2.7(19)$ & $2.1(19)$ \\
\hline$>50$ & $2.5(16)$ & $1.6(12)$ & $2.1(18)$ & $1.0(14)$ \\
\hline
\end{tabular}

Table 5 Crowding in home, fathers' social class, daughters' heights at age 7 years, and hazard ratios for coronary heart disease

\begin{tabular}{lcccc}
$\begin{array}{l}\text { No of people per } \\
\text { room }\end{array}$ & No of men & $\begin{array}{c}\text { Fathers in upper } \\
\text { social class } \mathbf{( \% )}\end{array}$ & $\begin{array}{c}\text { Daughters' heights } \\
\text { (cm) }\end{array}$ & $\begin{array}{c}\text { Daughters' hazard ratio } \\
\text { for coronary heart disease }\end{array}$ \\
\hline$\leqslant 1.5$ & 395 & 10.6 & 120.1 & 1.00 \\
\hline-2.5 & 855 & 3.9 & 119.5 & 1.00 \\
\hline-3.5 & 723 & 1.8 & 118.9 & 0.89 \\
\hline-4.5 & 520 & 1.2 & 118.3 & 0.25 \\
\hline$>4.5$ & 378 & 3.2 & 117.3 & 1.00 \\
\hline All & 3048 & 3.7 & 118.9 & - \\
\hline$P$ for trend & - & $<0.0001$ & $<0.0001$ & 0.64 \\
\hline
\end{tabular}

\section{Discussion}

In this study in Finland we have examined the paths of fetal and childhood growth that are associated with the later development of coronary heart disease in women. 
Table 6 Percentage of girls among term babies according to length and placental weight. Number of babies in parentheses

\begin{tabular}{llllll} 
& \multicolumn{5}{c}{ Length at birth (cm) } \\
\cline { 2 - 6 } Placental weight $(\mathbf{g})$ & $\leqslant \mathbf{4 8}$ & $\mathbf{- 4 9}$ & $-\mathbf{5 0}$ & $\mathbf{> 5 0}$ & All \\
\hline$\leqslant 500$ & $62(330)$ & $49(246)$ & $43(277)$ & $35(146)$ & $50(999)$ \\
\hline-600 & $64(299)$ & $57(342)$ & $53(627)$ & $38(539)$ & $51(1807)$ \\
\hline-700 & $66(134)$ & $55(255)$ & $53(595)$ & $38(774)$ & $48(1758)$ \\
\hline$>700$ & $69(42)$ & $60(98)$ & $55(350)$ & $43(904)$ & $48(1394)$ \\
\hline All & $64(805)$ & $55(941)$ & $52(1849)$ & $40(2363)$ & $49(5958)$ \\
\hline
\end{tabular}

Table 7 Percentage of boys among term babies according to head circumference and ponderal index. Number of babies in parentheses

\begin{tabular}{lllllc} 
& \multicolumn{5}{c}{ Head circumference $(\mathbf{c m})$} \\
\cline { 2 - 6 } Ponderal index $\left(\mathbf{k g} / \mathbf{m}^{\mathbf{3}}\right)$ & $<\mathbf{3 4}$ & $<\mathbf{3 5}$ & $<\mathbf{3 6}$ & $\mathbf{3 6}$ & All \\
\hline$\leqslant 25$ & $37(405)$ & $51(355)$ & $60(232)$ & $69(118)$ & $50(1110)$ \\
\hline-27 & $33(461)$ & $45(559)$ & $55(524)$ & $70(307)$ & $49(1851)$ \\
\hline-29 & $27(218)$ & $43(479)$ & $54(598)$ & $69(496)$ & $52(1791)$ \\
\hline$>29$ & $30(59)$ & $32(198)$ & $51(421)$ & $65(520)$ & $53(1198)$ \\
\hline All & $33(1143)$ & $44(1591)$ & $55(1775)$ & $68(1441)$ & $51(5950)$ \\
\hline
\end{tabular}

We found that these paths of growth differed from those of men in the same birth cohort who developed coronary heart disease. Because women have much lower rates of coronary heart disease we combined death and hospital discharge rates, whereas in our report on men we described only death rates. ${ }^{9}$ Among the women, however, the paths of growth associated with fatal and non-fatal disease were similar.

Our study was restricted to women who were born in Helsinki University Central Hospital. This would introduce a bias only if the associations between size at birth, childhood growth, and coronary heart disease differed between those born in the hospital and those born outside the hospital. The fathers of $85 \%$ of the women were classed as labourers. The women may therefore not be representative of all women living in Helsinki, although we know that in the early years of this century around $60 \%$ of men in the city were labourers. We ascertained coronary heart disease through the national mortality and national hospital discharge registers. The validity of these records has previously been reported. ${ }^{13} 14$

\section{Sex differences in fetal growth and coronary heart disease}

In keeping with findings among women in the United Kingdom, ${ }^{1}$ Sweden, ${ }^{2}$ the American nurses' study, ${ }^{3}$ and India $^{15}$ we found that coronary heart disease among women in the Helsinki cohort was associated with low birth weight (table 2 ). This trend was of only borderline significance, after adjustment for length of gestation, but it became strongly significant after adjustment for placental weight (table 3). Low birth weight therefore predicts coronary heart disease in both women and men. Our analysis of body proportions at birth, however, has shown that the paths of intrauterine growth that led to low birth weight and later coronary heart disease differed between the two sexes in the same cohort. The women were born short in length while the men were born thin; these associations being much stronger than those with birth weight. Stunting and thinness at birth may represent two different responses to fetal undernutrition, and published findings suggest that the long term consequences of these responses differ. While both have been found to be associated with raised blood pressure in later life, ${ }^{16} 17$ stunting is associated with persistent changes in liver function, including raised serum cholesterol concentration $^{18}$ and plasma fibrinogen, ${ }^{19}$ while thinness is associated with features of the insulin resistance syndrome including impaired glucose tolerance and dyslipidaemia. ${ }^{20}$

We found that the paths of fetal growth among women and men in this cohort differed. The small sex differences in average body measurements at birth (table 1) concealed large differences in body proportions (tables 6 and 7). Girls tended to be short in relation to their placental size; boys tended to be thin in relation to their head circumference. As the girls and boys were born to the same group of mothers these differences in body proportions must reflect intrinsic differences between the sexes in their paths of growth at similar levels of maternal nutrition. The rate of fetal growth of girls and boys is known to differ from an early stage of gestation, even from before implantation. $^{10}{ }^{11} 21$ Girls grow more slowly. Because different parts of the body grow at different phases of gestation, sex differences in growth rates could lead to differences in body proportions at birth. In animals the rate of intrauterine growth is known to modify the effects of a brief period of maternal undernutrition on the offspring's body composition at birth. ${ }^{22}{ }^{23}$

\section{Sex differences in childhood growth and coronary heart disease}

In both women and men the effects of reduced fetal growth on the risk of coronary heart disease were increased by accelerated or "catch up" growth. Among women the effect of being short at birth was greatest in those who were tall in childhood (table 4). Men who were thin at birth increased their risk by having an above average body mass index in childhood. The risk among women was not influenced by body mass in childhood, and risk among men was not influenced by height. In our previous report we discussed several possible reasons why catch up growth could be associated with adverse outcomes in later life. ${ }^{9}$ One speculation is based on the observation that restricted fetal growth leads to permanently reduced cell numbers in tissues such as kidney, in which there is no further cell replication after birth. ${ }^{24}$ Postnatal catch up growth could be deleterious either because overgrowth of a limited cell mass disrupts cell function or because large body size imposes an excessive metabolic demand on a limited cell mass.

The childhood heights of the women were related to their mothers' heights, and the interaction between short length at birth and tallness in childhood in increasing the risk of coronary heart disease was stronger in the daughters of taller mothers. This could reflect both nutritional and genetic influences, the nutritional benefits associated with a taller, heavier mother being either direct effects during lactation or better availability of food after weaning. We used the level of crowding in the home as an index of living conditions. Women who grew up in less crowded homes were taller at all ages. The level of crowding was not, however, related to later coronary heart disease (table 5). Our findings therefore suggest that it is good nutrition and genetic influences rather than living conditions and low rates of infection that lead to catch up 
Key messages

- Coronary heart disease in women is associated with low birth weight but more strongly with short body length at birth

- Among men in the same cohort coronary heart disease is also associated with low birth weight but more strongly with thinness at birth

- In the whole cohort body proportions at birth differed in the two sexes: the girls were short and the boys were thin

- These differences may reflect intrinsic sex differences in rates of fetal growth at similar levels of maternal nutrition

- The slower fetal growth of females may underlie their lower rates of coronary heart disease

growth in height and increased risk of later coronary heart disease in women. A similar suggestion came from our analyses of the men, among whom catch up in weight was associated with high maternal body mass. ${ }^{9}$ We conclude that coronary heart disease among both the women and men in our study reflected poor prenatal nutrition combined with improved postnatal nutrition.

\section{Sex differences in coronary heart disease}

We have found that coronary heart disease among women and men is associated with the body proportions at birth that distinguish the two sexes. Women who develop coronary heart disease were short at birth, particularly in relation to placental weight; the men were thin. It has been suggested that the growth of every human fetus is constrained by the mother through her limited capacity to deliver nutrients to it. ${ }^{25}$ In the light of this, coronary disease could represent the outcome of more severe constraint to which female and male fetuses respond differently because female fetuses grow more slowly. By the time of birth the girls have become short and the boys thin. The long term changes in physiology and metabolism associated with shortness and thinness at birth are different, and so too it seems are the adverse effects of catch up growth in height and weight during childhood. The lower rates of coronary heart disease among women may originate in their slower rates of growth in utero.

We thank Terttu Nopanen, Tiina Saarinen, Hillevi ÖfverströmAnttila, Liisa Toivanen, Arja Purtonen, Tiina Valle, Hanna Pehkonen, and Ulla Tarvainen for abstracting the data from the records. Sigrid Rosten was responsible for data management

Contributors: All the authors took part in the design and analysis of the study and jointly wrote the paper. The data abstraction and linkage were supervised by JGE and TF. JGE, $\mathrm{CO}$, and $\mathrm{DJPB}$ will act as guarantors for the paper.

Funding: British Heart Foundation, Jahnsson Foundation, Finska Läkaresällskapet, Orion Corporation Research Foundation, and Finnish Foundation for Cardiovascular Research. Competing interests: None declared.

1 Osmond C, Barker DJP, Winter PD, Fall CHD, Simmonds SJ. Early growth and death from cardiovascular disease in women. BMJ 1993;307: 1519-24.
2 Leon D, Lithell HO, Vagero D, Koupilova I, Mohsen R, Berglund L, et al. Reduced fetal growth rate and increased risk of death from ischaemic heart disease: cohort study of 15000 Swedish men and women born 1915-29. BMJ 1998;317:241-5.

3 Rich-Edwards JW, Stampfer MJ, Manson JE, Rosner B, Hankinson SE, Colditz GA, et al. Birth weight and risk of cardiovascular disease in a cohort of women followed up since 1976. BMJ 1997;315:396-400.

4 Barker DJP. Fetal origins of coronary heart disease. BMJ 1995;311:171-4.

5 Barker DJP. Mothers, babies and health in later life. 2nd ed. Edinburgh: Churchill Livingstone; 1998

6 Harding JE, Johnston BM. Nutrition and fetal growth. Reprod Fertil Dev 1995;7:539-47.

7 Martyn CN, Barker DJP, Osmond C. Mothers' pelvic size, fetal growth, and death from stroke and coronary heart disease in men in the UK. Lancet 1996:348:1264-8.

8 Forsén T, Eriksson JG, Tuomilehto J, Teramo K, Osmond C, Barker DJP. Mother's weight in pregnancy and coronary heart disease in a cohort of Finnish men: follow up study. BMJ 1997;315:837-40.

9 Eriksson JG, Forsén T, Tuomilehto J, Winter PD, Osmond C, Barker DJP Catch up growth in childhood and death from coronary heart disease: longitudinal study. $B M J$ 1999;318:427-31.

10 Tanner JM. Foetus into man. 2nd ed. Castlemead: Ware,1989.

11 Pedersen JF. Ultrasound evidence of sexual difference in fetal size in first trimester. BMJ 1980;281:1253.

12 Royston P. Constructing time-specific reference ranges. Stat Med 1991;10:675-90.

13 Mahonen M, Salomaa V, Brommels M, Molarius A, Miettinen H, Pyorala $\mathrm{K}$, et al. The validity of hospital discharge register data on coronary heart disease in Finland. Eur J Epidemiol 1997;13:403-15.

14 Rapola JM, Virtamo J, Korhonen P, Haapakoski J, Hartman AM, Edwards BK, et al. Validity of diagnoses of major coronary events in national registers of hospital diagnoses and deaths in Finland. Eur J Epidemio 1997;13:133-8

15 Stein CE, Fall CHD, Kumaran K, Osmond C, Cox V, Barker DJP. Fetal growth and coronary heart disease in South India. Lancet 1996;348: 1269-73.

16 Barker DJP, Godfrey KM, Osmond C, Bull A. The relation of fetal length, ponderal index and head circumference to blood pressure and the risk of hypertension in adult life. Paediatr Perinat Epidemiol 1992;6:35-44

17 Martyn CN, Barker DJP, Jespersen S, Greenwald S, Osmond C, Berry C. Growth in utero, adult blood pressure, and arterial compliance. Br Hear J 1995;73:116-21.

18 Barker DJP, Martyn CN, Osmond C, Hales CN, Fall CHD. Growth in utero and serum cholesterol concentrations in adult life. $B M J$ $1993 ; 307: 1524-7$

19 Martyn CN, Meade TW, Stirling Y, Barker DJP. Plasma concentrations of fibrinogen and factor VII in adult life and their relation to intra-uterine growth. Br J Haematol 1995;89:142-6.

20 Lithell HO, McKeigue PM, Berglund L, Mohsen R, Lithell UB, Leon DA Relation of size at birth to non-insulin dependent diabetes and insulin concentrations in men aged 50-60 years. BMJ 1996;312:406-10.

21 Garn SM, Burdi AR, Babler WJ. Male advancement in prenatal head development. Am J Phys Anthropol 1974;41:353-9.

22 Harding J, Liu L, Evans P, Oliver M, Gluckman P. Intrauterine feeding of the growth retarded fetus: can we help? Early Hum Dev 1992;29:193-7.

23 Widdowson EM, McCance RA. The effect of finite periods of undernutrition at different ages on the composition and subsequent development of the rat. Proc Roy Soc Lond B 1963;158:329-42.

24 Pitts GC. Cellular aspects of growth and catch-up growth in the rat: a reevaluation. Growth 1986;50:419-36.

25 Ounsted M, Scott A, Ounsted C. Transmission through the female line of a mechanism constraining human fetal growth. Ann Hum Biol 1986;13:143-51.

(Accepted 24 August 1999)

\section{Endpieces}

\section{Alternative therapies}

Am receiving ionisation treatment from an electrical therapeutist-a quack! He is a sort of electrician-still, if he mends my bells I'll kiss his boots .... This is not the first time I have felt driven to act behind the back of the Profession. In 1912 , being desperate ... went to see a homoeopathist in Finsbury Circus. He proved to be a charlatan at $10 \mathrm{~s} .6 \mathrm{~d}$ a time, and tho' I realised it at once, I religiously travelled about for a month or more with tinctures and drop-kettle. I could write a book on the Doctors I have known and the blunders they have made about me.

W N P Barbellion, The Journal of a Disappointed Man.London: Chatto and Windus, 1919.

Submitted by J Aronson, clinical pharmacologist Oxford 